\title{
Aspectos indicadores de qualidade ambiental nos espaços abertos de jardins zoológicos: estudo de percepção no Parque Zoológico da FZB/RS
}

\author{
Aspects of environmental quality in the zoos open spaces: \\ a perception study in the FZB/ RS Zoological Park
}

\section{Samantha Balleste Natalia Naoumova}

\section{Resumo}

A s funções de educação e entretenimento ao público, presentes nos jardins zoológicos atuais, demandam ambientes dinâmicos e prazerosos, capazes de permitir uma formação completa do indivíduo. É essencial para que a experiência seja educativa e memorável ir ao encontro dos interesses do público e proporcionar um espaço qualificado. No entanto, há carência de estudos que abordem a qualidade espacial nessas instituições, baseados em avaliações envolvendo as pessoas que utilizam o espaço. Desse modo, o presente estudo tem como objetivo investigar os aspectos físicoespaciais que influenciam na qualidade dos espaços abertos de jardins zoológicos, a partir da percepção dos seus visitantes. Inserido nas áreas de estudo das relações ambiente-comportamento e da avaliação pós-ocupação, o trabalho adota uma abordagem metodológica qualitativa e quantitativa e é conduzido a partir de um estudo de caso, o Parque Zoológico da FZB/RS, localizado em Sapucaia do Sul, Brasil. A satisfação dos visitantes é considerada como medida de desempenho ambiental. Como resultado foram identificados os principais aspectos físicoespaciais que mais influenciam na satisfação dos visitantes, sendo eles agradabilidade, organização e interesse do espaço, instalações de apoio aos visitantes e naturalidade do espaço.

Palavras-chave: Jardins zoológicos. Espaços abertos. Percepção ambiental. Satisfação.
${ }^{1}$ Samantha Balleste ${ }^{1}$ Instituto Federal Sul-Rio-Grandense Pelotas - RS - Brasil https:// orcid. org/ 0000-0002-8366-2928

${ }^{2}$ Natalia Naoumova 2 Universidade Federal de Pelotas Pelotas - RS - Brasil

Recebido em 20/11/18

Aceito em 18/04/19

\section{Abstract}

The functions of education and entertainment of the public, which are present in zoological gardens today, demand dynamic and pleasant environments that are able to allow individuals a holistic educational experience. If that experience is to be educational and memorable, it is essential to meet the public's interests and offer it a quality space. There is, however, a lack of studies addressing the spatial quality of these institutions, based on evaluations involving the people who use the spaces. Based on the perception of its visitors, this study aims to investigate the physical-spatial aspects that influence the performance of the zoo's open spaces. Inserted in the study area of Environment-Behaviour Relations and Evidence-Based Design, this study adopted a qualitative and quantitative methodological approach and conducted a case study in the Zoological Park of the FZB/RS, located in Sapucaia do Sul, Brazil. Visitor's satisfaction is considered a measure of environmental performance. The study found that the main physical-spatial aspects that influence visitor satisfaction were the pleasantness, organisation and interest of the space, the facilities for visitors and the naturalness of the space.

Keywords: Zoological gardens. Open spaces. Environmental perception. Satisfaction.

BALLESTE, S.; NAOUMOVA, N. Aspectos indicadores de qualidade ambiental nos espaços abertos de jardins zoológicos: 79 estudo de percepção no Parque Zoológico da FZB/ RS. Ambiente Construído, Porto Alegre, v. 19, n. 4,

p. 79-94, out./ dez. 2019.

ISSN 1678-8621 Associação Nacional de Tecnologia do Ambiente Construído.

http:// dx. doi.org/ 10.1590/ s1678-86212019000400344 


\section{Introdução}

Nas sociedades urbanas em que vivemos, o contato das pessoas com a natureza e principalmente com a vida animal está se tornando cada vez mais raro. Assim, a possibilidade proporcionada pelos jardins zoológicos contemporâneos, localizados no meio urbano, de passear ao ar livre em plena natureza e poder ao mesmo tempo desfrutar da presença de animais selvagens provenientes de diferentes locais do mundo é altamente valorizada (WILLIAMS et al., 2012). Destaca-se que os jardins zoológicos podem ser vantajosos para as pessoas que vivem em lugares considerados estressantes, como grandes centros urbanos, podendo ajudar essas pessoas a manter o seu bem-estar físico e psicológico (ROBINETTE et al., 2017).

Além do valor social, destaca-se também a longa história de liderança ecológica dos jardins zoológicos. Ao promoverem uma educação verde, fornecendo informações essenciais sobre a distribuição dos animais, sobre os seus habitats e comportamentos naturais, essas instituições acabam por despertar um sentimento de sustentabilidade, inspirando os visitantes a fazerem escolhas que beneficiem todas as espécies que compartilham o planeta (COE, 2011).

Os jardins zoológicos contemporâneos têm como principais finalidades a educação e o entretenimento do público, a conservação das espécies e a realização de pesquisas (EBENHÖH, 1992; HANCOCKS, 2003), uma vez que a educação e o entretenimento dos visitantes são geralmente atribuídos a encontros pessoais com os animais. No entanto, Ebenhöh (1992) aponta que embora as exposições sejam uma parte importante da experiência, as áreas abertas entre as exposições e lugares convenientes para ficar e desfrutar o passeio são altamente significativos para as pessoas, e tão importantes quanto às exposições em si. Um lugar atrativo, com qualidade espacial, tende a atrair mais indivíduos do que lugares pouco qualificados, pois as pessoas são capazes de reconhecer os lugares mais vantajosos para si (HAAS, 2000). Desse modo, entende-se que a qualidade da visitação deve ser um dos itens fundamentais no planejamento de jardins zoológicos. Esses espaços necessitam ser pensados a fim de proporcionar múltiplas sensações aos seus visitantes, pois quando bem qualificados, ou seja, com ambientes dinâmicos, sensoriais e prazerosos, podem possibilitar melhor absorção das informações educativas.

Diversos referenciais teóricos que auxiliam na idealização dos espaços de jardins zoológicos podem ser encontrados em revistas especializadas, tais como o International Zoo Yearbook, nos jornais
Zoo Biology, Curator, Architecture, Landscape Architecture e Environmental Psychology. Contudo, na maioria desses estudos a percepção dos visitantes sobre o espaço aberto do jardim zoológico como um todo não é levada em consideração. A maior parte das informações disponíveis é resultado de avaliações técnicas, ou seja, a visão do pesquisador após observar um ou mais jardins zoológicos e avaliar a reação das pessoas frente aos recintos dos animais. No Brasil, a escassez de dados é ainda maior, pois a área do design de jardins zoológicos ainda está em emersão, e a necessidade de tais investigações não é vista como relevante por parte dos arquitetos e pesquisadores da área.

Desse modo, o problema central desta investigação se estabelece pela carência de estudos e subsídios teóricos que relacionem a qualidade dos espaços abertos com a satisfação das pessoas que visitam os jardins zoológicos. Tem-se como objetivo identificar, a partir da percepção dos seus visitantes, quais aspectos dos espaços abertos de jardins zoológicos estão mais fortemente ligados à percepção de qualidade ambiental e como eles contribuem para seu reconhecimento como um lugar qualificado. O termo "qualidade" é definido na NBR ISO 9000 (ABNT, 2015) como “[...] a totalidade de características de uma entidade que lhe confere a capacidade de satisfazer as necessidades explícitas e implícitas [...]”. Sendo assim, neste estudo a medida de desempenho ambiental considerada a medida-chave para avaliar o espaço é a satisfação.

\section{Processo de avaliação do ambiente pelos indivíduos}

A área de estudos da Psicologia Ambiental e das Relações Ambiente-Comportamento, na qual esta pesquisa se baseia, concentra-se na investigação dos processos de interação entre as características físico-espaciais do ambiente e as respostas comportamentais dos indivíduos que utilizam esse ambiente. Para designar esses processos, é empregado o termo percepção ambiental. O processo de percepção ambiental como um todo envolve várias etapas e experiências sequenciais, das quais duas se destacam: a percepção e a cognição (LANG, 1987; NASAR, 1992).

As experiências perceptivas são compreendidas como uma atividade sensório-motora, e referem-se à apreciação do mundo externo como estímulo presenciado no momento, algo imediatamente observado ou sentido através dos sentidos básicos, como visão, olfato, audição, tato e paladar. Ocorrem independentemente de operações internas como 
memória, reconhecimento e imaginação. As experiências cognitivas são consideradas complementares à percepção, e entendidas como a maneira que o objeto percebido é codificado, armazenado e organizado na mente do observador. A cognição não envolve, necessariamente, uma atitude diretamente relacionada ao que está ocorrendo no espaço visualizado, ela implica associações e significados gerados por atributos ambientais. A experiência prévia do indivíduo, características como idade, gênero, educação, cultura e classe social e preferências, interferem significativamente nos processos cognitivos.

As informações obtidas através das experiências perceptivas e cognitivas resultam em uma imagem ambiental (GOLLEDGE; STIMSOM, 1997), e a área de estudos da Psicologia Ambiental e das Relações Ambiente-Comportamento tem como uma de suas premissas que é possível melhor entender as ações, necessidades e aspirações das pessoas em relação ao ambiente, a partir do conhecimento sobre como essa imagem ambiental é concebida. Assim, compreende-se que a percepção de qualidade do ambiente surge como consequência das imagens ambientais que se têm do local, e de como e por quem essas imagens são apreendidas.

O processo de percepção ambiental em jardins zoológicos segue um padrão definido: as pessoas entram no ambiente, imediatamente o percebem e logo tentam dar sentido a ele avaliando as informações recebidas. O próximo passo é a transformação das informações em conhecimento (GAGNE, 1985; GRAETZ, 1995). Entretanto, os estudos empíricos indicam que as pessoas podem ou não estar visitando o jardim zoológico com a intenção de aprender, e esse entendimento é o primeiro passo para planejar o espaço com sucesso.

Atualmente os jardins zoológicos são vistos como locais propícios para estudos de percepção e cognição ambiental, comportamento, avaliação da paisagem, entre outros (KAPLAN; KAPLAN, 1983; GRAETZ, 1995). Neste estudo, utiliza-se a abordagem perceptiva e cognitiva para avaliar o desempenho dos espaços abertos de jardins zoológicos a partir dos elementos físico-espaciais presentes nesses ambientes. Analisa-se a avaliação feita pelos indivíduos com a finalidade de entender quais e como os atributos ambientais contribuíram para essa avaliação.

\section{Avaliação pós-ocupação}

A avaliação pós-ocupação (APO) refere-se a um conjunto de métodos e técnicas utilizadas para a avaliação de desempenho dos ambientes. A partir da avaliação de fatores técnicos, funcionais, econômicos, estéticos e comportamentais do ambiente, além da avaliação de desempenho tradicional, realizada por técnicos, são diagnosticados os fatores positivos e negativos do ambiente (ORNSTEIN; ROMERO, 1992). A partir dos resultados dessas avaliações, é possível elaborar recomendações para o próprio estudo de caso e fazer generalizações. Ornstein e Roméro (1992) afirmam que nessa abordagem o conceito de desempenho pressupõe $o$ atendimento das necessidades e expectativas das pessoas que utilizam o espaço, enquanto a qualidade está associada ao desempenho satisfatório dos ambientes.

Segundo Rheingantz et al. (2009), há oito instrumentos de avaliação e coleta de dados que se destacam como os mais utilizados na APO, sendo eles o questionário, a entrevista, o walkthrough, o mapa comportamental, o poema dos desejos, o mapeamento visual, o mapa mental e a seleção visual. O questionário é um método que permite coletar grandes quantidades de dados e que possibilita produzir generalizações. A entrevista trata de uma conversação, com um determinado objetivo, que permite explorar os sentimentos e as atitudes da pessoa pesquisada. O walkthrough é definido como uma entrevista caminhada, complementada por fotografias, áudios e vídeos. $\mathrm{O}$ mapa comportamental tem o intuito de sistematizar o registro de localização e atividades das pessoas nos ambientes, ilustrando empiricamente o uso do espaço, o percurso dos indivíduos e as regularidades nos seus comportamentos. O poema dos desejos é um método pelo qual os indivíduos de um determinado ambiente podem declarar, por meio de um conjunto de desenhos, suas necessidades, emoções, afetos, simbolismos e desejos relativos ao ambiente ou edifício analisado, sem a necessidade de palavras. O mapeamento visual permite identificar a percepção dos indivíduos com foco na sua localização, na apropriação e na demarcação de territórios. O mapa mental consiste na elaboração de desenhos de memória representativas sobre um determinado lugar. Já a seleção visual refere-se à utilização de imagens referenciais previamente escolhidas para a avaliação.

Considera-se que os métodos e técnicas da avalição pós-ocupação são eficazes na área de estudos das Relações Ambiente-Comportamento para avaliação de ambientes, e, desse modo, estes serão 
instrumentos de avaliação e coleta de dados utilizados neste estudo.

\section{Satisfação e os requisitos agradabilidade, organização e interesse}

A satisfação das pessoas que utilizam o espaço tem sido apontada como critério fundamental de espaços abertos bem-sucedidos. Segundo Castello (2007), as pessoas possuem fortes relações psicológicas com os espaços, e estes determinam se irão se sentir bem ou mal em determinados ambientes. Está associada ao julgamento ou à atitude em relação a uma situação presente, referindo-se a algo que está sendo vivido e que não precisa ser comparativo, pois o indivíduo pode avaliar a qualidade de um lugar independentemente de comparação (NASAR, 1992).

A satisfação como critério de medição do desempenho ambiental frequentemente costuma avaliar:

(a) o nível de satisfação do indivíduo com uma determinada característica do ambiente; e

(b) a importância de tal característica para a satisfação geral com o local.

Esses dois tipos de avaliação são utilizados neste estudo.

A qualidade visual (estética) é um dos requisitos de ambientes abertos qualificados, e considerada influenciadora da satisfação dos indivíduos (REIS; LAY, 2006). Com base na discussão da literatura, é adotado neste estudo que a percepção da qualidade visual de um ambiente é uma construção psicológica relacionada às avaliações feitas pelos indivíduos que utilizam esse ambiente. No contexto da resposta estética e formação das preferências, a literatura indica como dimensões avaliativas mais relevantes a agradabilidade, a ordem e o interesse proporcionados pelo espaço.

A agradabilidade é uma dimensão puramente avaliativa, sendo por vezes considerada como o único sentimento relacionado com o julgamento de beleza. O termo agradável refere-se a algo "que dá prazer aos sentidos”, e, assim, agradabilidade faz referência ao sentimento de prazer propriamente dito (LANG, 1987; NASAR, 1992; STAMPS, 2000). O estudo de agradabilidade neste trabalho busca identificar a influência da aparência do espaço na satisfação dos visitantes. No caso dos jardins zoológicos, essa característica é relacionada à aparência dos elementos e espaços, e de suas características como materiais, cores, formas e elementos compositivos.
A ordem está relacionada à configuração e ao grau de ordenamento dos espaços (KAPLAN; KAPLAN, 1983). Refere-se à compreensão da organização e à legibilidade do ambiente, ou seja, em como o ambiente é compreendido pelos indivíduos.

O interesse refere-se a algo "atraente, que prende a atenção, que desperta a curiosidade" (NASAR, 1992; WEBER, 1995). Estudos empíricos indicam que animais, elementos brilhantes, objetos em movimento ou que produzem sons altos e ambientes complexos, com grande quantidade de estímulos visuais, são aspectos relacionados à produção dessa característica (KAPLAN; KAPLAN, 1983; EBENHÖH, 1992). Desse modo, neste estudo a qualidade ambiental (satisfação) do espaço é medida através dos requisitos agradabilidade, organização e interesse proporcionados.

\section{Satisfação e as características de design dos jardins zoológicos}

\section{Histórico e caracterização dos jardins zoológicos}

Ao longo do tempo os jardins zoológicos passaram por muitas mudanças, não apenas no sentido físico, mas também nos seus conceitos. Os jardins zoológicos do início do século XX em grande parte foram estabelecidos seguindo os preceitos da Sociedade Zoológica de Londres, na qual os princípios científicos e educativos eram influentes e a organização espacial era orgânica e informal (BARATAY; HARDOUIN-FUGIER, 2002; HANCOCKS, 2003).

Na década de 1930, com a chegada do Movimento Moderno, o design dos jardins zoológicos passou por intensas modificações. Assim como nas cidades (DEL RIO, 1990), esse movimento denominado "Era Desinfetante" na história dos jardins zoológicos foi uma fase em que esses ambientes adotaram uma "pureza científica”, em que a forma vinha antes da função. Na proposta modernista, o zoológico é um espaço composto de uma série de recintos esculturalmente construídos, em que os animais serviam apenas para animar a precisão das formas e técnicas de uso dos materiais construtivos.

Na década de 1970, sob influência do movimento ambiental, a ecologia e a conservação da natureza se tornaram os princípios básicos para a gestão e o planejamento dos jardins zoológicos, fazendo surgir um novo conceito denominado imersão na paisagem. Esse conceito trata a natureza com mais ênfase e é regido pela intenção de criar perfeitas ilusões de paisagens, não apresentando separação visível entre as áreas dos animais e dos visitantes (EBENHÖH, 1992; HANCOCKS, 2003). As 
estratégias de desenho e planejamento que apoiam esse conceito têm como uma das principais intenções chegar ao lado emocional do público e só depois o seu lado intelectual, fazendo-o imergir física e psicologicamente no habitat natural. As premissas da imersão na paisagem permanecem em uso nos jardins zoológicos contemporâneos, no entanto atualmente recebe a denominação de design imersivo (COE, 2012).

De acordo com essa linha de pensamento, e levando-se em consideração que os jardins zoológicos são formados principalmente por espaços abertos, é essencial que ele seja planejado em sua totalidade para que o visitante se sinta envolvido no ambiente apresentado (EBENHÖH, 1992; COE, 2000, 2011, 2012; HANCOCKS, 2003). De acordo com Ebenhöh (1992), os visitantes dos jardins zoológicos contemporâneos desejam, basicamente, uma experiência agradável, divertida e educativa, em meio à natureza.

\section{Principais elementos e características de design dos espaços abertos de jardins zoológicos}

No planejamento dos espaços abertos dos jardins zoológicos contemporâneos destacam-se variadas características e elementos físicos de design. Estes elementos foram agrupados pela pesquisadora em sete categorias:

(a) instalações de apoio aos visitantes;

(b) elementos dos recintos;

(c) vegetação e recursos naturais;

(d) mobiliários;

(e) recursos recreativos;

(f) elementos de circulação; e (g) dispositivos de orientação espacial (BITGOOD, 1988; EBENHÖH, 1992; GRAETZ, 1995).

Todas as categorias citadas foram consideradas para análise neste estudo, sendo em relação ao nível de satisfação do indivíduo com uma determinada característica e também pela importância de tal característica para a satisfação geral com o espaço.

Instalações de apoio são traduzidas em espaços como áreas de exposição, que ocupam uma média de $60-70 \%$ do território, mas também áreas de descanso, estacionamentos, restaurantes, áreas de piquenique, banheiros, quiosques de informação, lojas de lembrancinhas, edifício de educação ambiental e pracinhas.

Elementos dos recintos são as barreiras entre o público e os animais, sendo as mais comuns as estruturas de malha metálica (flexível ou rígida) e os fossos, os corrimãos, a vegetação e as estruturas de enriquecimento ambiental (Figura 1).

Vegetação e recursos naturais são as plantas de diferentes portes e a água. A função desses elementos pode ser de:

(a) definição de espaços (conduzir, focar, destacar, entre outros);

(b) criação de microclimas;

(c) utilização como elementos decorativos;

(d) elemento recreativo para os animais e visitantes;

(e) elemento educativo para os visitantes;

(f) para oferecer fragrâncias;

(g) sugerir visuais;

(h) proporcionar variedade ambiental (cores e texturas); e

(i) simular os habitats naturais dos animais.

Figura 1 - Barreiras de malha em recintos de jardins zoológicos

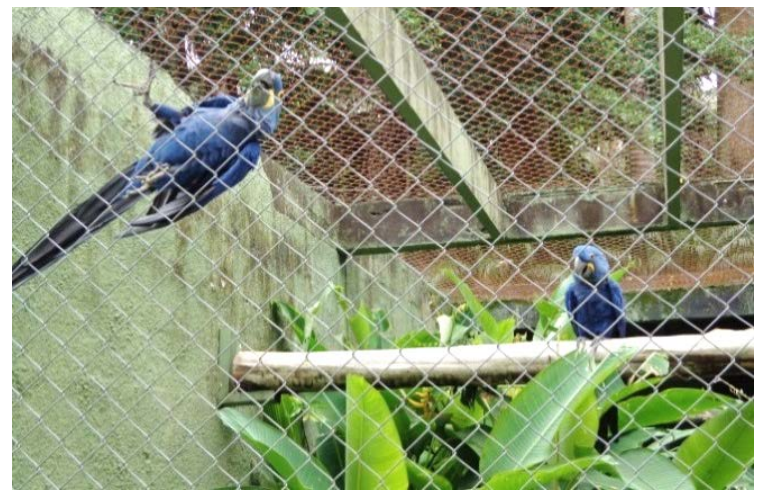

(a) Recinto barreira de tela metálica

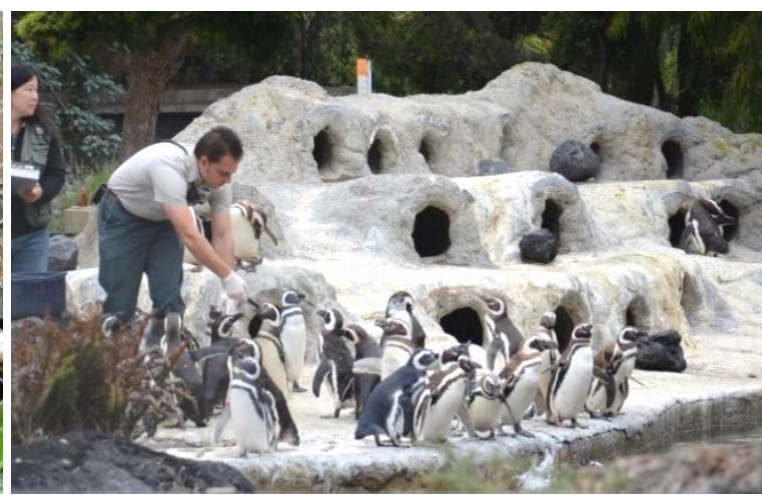

(b) Elemento de enriquecimento ambiental 
A água é usada em uma ampla variedade de combinações, e em conjunto com a vegetação pode transmitir ao público uma sensação de fluidez, naturalidade e relaxamento (Figura 2).

Mobiliários são equipamentos instalados nos espaços para diversos propósitos. Os mais encontrados nos jardins zoológicos são bancos, lixeiras, luminárias e bebedouros.

Recursos recreativos são dispositivos de entretenimento e aprendizagem que oferecem a possibilidade de interação. Podem ser encontrados em jardins zoológicos: painéis e pinturas, jogos de entretenimento educacional, esculturas e outros elementos educativos e também pracinhas para crianças. As pracinhas podem ser concebidas como simples, coloridas ou com alguma temática, que contribui para a educação das crianças (Figura 3).

Elementos de circulação são os relacionados às características dos caminhos, tais como direção, largura dos caminhos (fluxo), tipo de pavimentação, acessibilidade e necessidade de implantação de pontes, escadas e observatórios.

Dispositivos de orientação espacial são os elementos que auxiliam as pessoas a se localizarem no ambiente. Os mais comuns nos jardins zoológicos são sinais direcionais, os de identificação e os educacionais, os mapas de "você está aqui” e os mapas de mão.

\section{Método}

Para alcançar o objetivo da pesquisa, é utiliza uma abordagem metodológica qualitativa e quantitativa, que permite, através de um estudo de caso, conhecer mais profundamente um aspecto investigado, com base em levantamentos e na observação de eventos. São utilizados para levantamentos de dados métodos e técnicas da APO, pois essa abordagem é considerada eficaz na área de estudos das Relações Ambiente-Comportamento para avaliação de ambientes (REIS; LAY, 2006; RHEINGANTZ et al., 2009).

Figura 2 - Uso de vegetação e água em jardins zoológicos

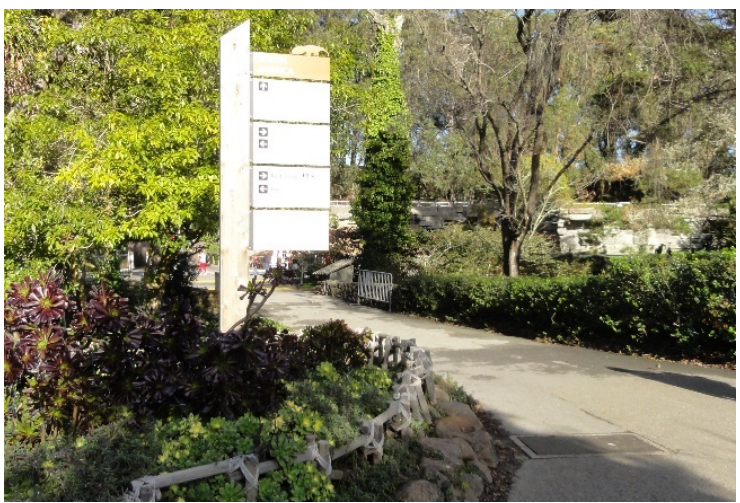

(a) Plantio nos caminhos

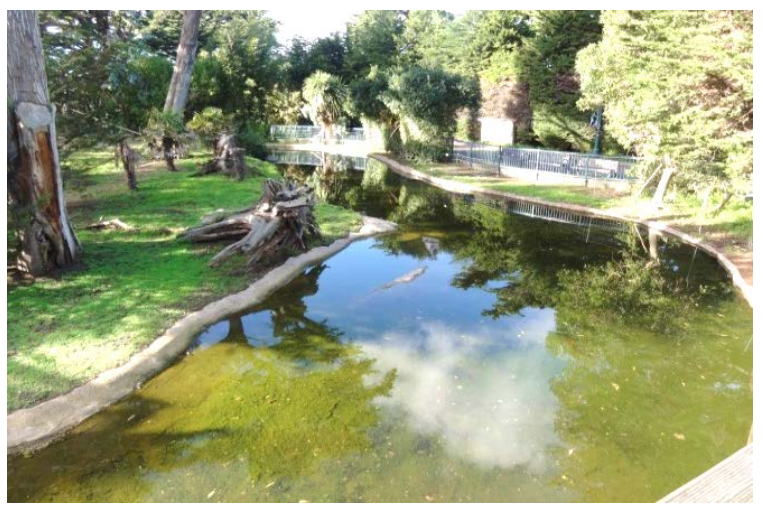

(b) Lagos

Figura 3 - Dispositivos de entretenimento e aprendizagem em jardins zoológicos

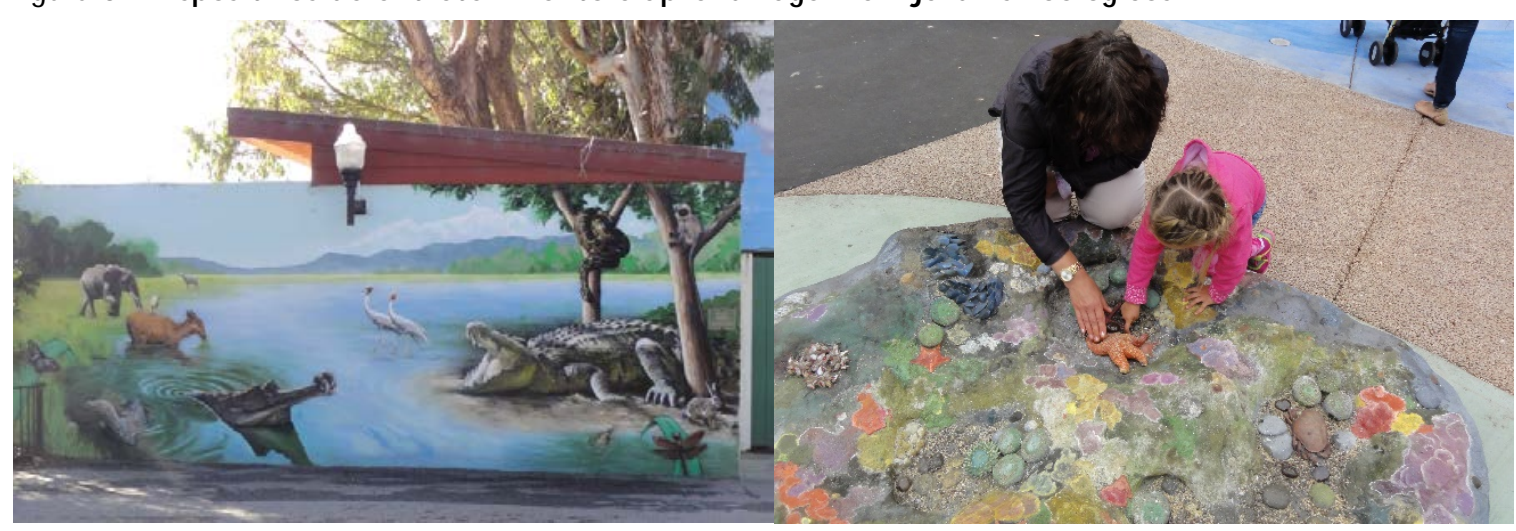

(a) Pintura de paisagem de habitat natural

(b) Escultura educativa 
A investigação conta com três métodos de levantamento de dados:

(a) levantamento físico: em que foram feitas medições físicas e registro fotográfico das características formais e elementos físicos do design presentes no espaço aberto do jardim zoológico para complementar os dados disponíveis previamente;

(b) questionário: realizado a fim de identificar os aspectos do ambiente que apresentam uma maior influência na satisfação das pessoas, e que, assim, contribuem para a percepção de qualidade do ambiente; e

(c) entrevista: realizada para aprofundar informações levantadas pelo questionário.

A amostra de pessoas do estudo é de oportunidade, inclui os visitantes de jardins zoológicos, e é limitada entre as faixas etárias adolescentes/adultos/idosos (13-17/18-59/acima de 60 anos). A quantidade e características dos participantes em cada técnica de coleta de dados avaliativos são apresentadas na Tabela 1.

O questionário elaborado na pesquisa foi estruturado em duas partes. A primeira parte, sobre a visitação, é composta de oito questões de múltipla escolha, todas utilizando a escala de Likert de cinco pontos. A primeira pergunta é uma questão geral sobre a satisfação com a visita: "1. Você ficou satisfeito com a visita ao Parque Zoológico?”. As duas perguntas seguintes referem-se à avaliação da aparência do espaço, sua organização e o interesse proporcionado: "2. De modo geral a aparência do Parque Zoológico é?”, e “3. Na sua opinião, o Parque Zoológico é: (A) sobre organização e (B) sobre interesse". A quarta pergunta busca avaliar a satisfação dos visitantes quanto às instalações de apoio citadas: "4. Como você avalia as seguintes áreas do Parque Zoológico: a) área de exposições, b) área do estacionamento, c) área de alimentação, d) área de piquenique, e e) área da pracinha?”. A quinta pergunta busca avaliar a importância de determinadas características de design para a satisfação dos visitantes “5. Qual a importância dos itens a seguir para a sua satisfação na visita ao Parque Zoológico? (i) presença de vegetação, (ii) presença de lagos e riachos, (iii) diversidade de ambientes, (iv) lugares para explorar a natureza, (v) caminhos divertidos, (vi) acessibilidade, (vii) largura e tipo de pavimentação dos caminhos, (viii) mapas e placas de indicação de caminhos, (ix) visualização dos animais e $(x)$ possibilidade de realizar atividades variadas”. A sexta pergunta diz respeito à avaliação de agradabilidade da vegetação e das fontes de água: “6. Avalie a vegetação e as fontes de água do Parque Zoológico: (A) vegetação $e$ (B) fontes de água”. A sétima e oitava perguntas referem-se à avaliação quanto a disponibilidade e aparência dos mobiliários (bancos e lixeiras): “7. Como você avalia a disponibilidade de bancos $e$ lixeiras no Parque Zoológico?”, e, “8. Qual a sua opinião sobre a aparência de bancos e lixeiras do Parque Zoológico? (a) bancos e (b) lixeiras”.

A segunda parte do questionário refere-se ao perfil do respondente, e conta com seis perguntas: "9. Primeira vez visitando o Parque Zoológico?”, “10. Sua faixa etária”, “11. Seu gênero”, “12. Qual o meio de transporte você utilizou para vir ao Parque Zoológico?”, “13. O que motivou sua visita ao Parque Zoológico?”, e “14. Gostaria de deixar algum comentário?”.

A entrevista elaborada na pesquisa possui quatro perguntas: "1. Você se sentiu satisfeito após a visita ao Parque Zoológico?”, “2. Quanto ao espaço físico do Parque Zoológico, quais os aspectos de que você mais gostou?", "3. De quais aspectos físicos você menos gostou? ”, e "4. Você acha que os caminhos do Parque Zoológico são divertidos e interessantes? Explique o porquê".

A técnica escolhida para aplicação dos métodos avaliativos é a feita pessoalmente e individualmente aos visitantes do Parque Zoológico no próprio local de estudo e em dias de maior visitação. As entrevistas foram gravadas no momento da aplicação para possibilitar a posterior transcrição e análise.

Tabela 1 - Amostra de participantes em cada técnica de coleta de dados

\begin{tabular}{l|c|c|c|c|c|c}
\hline \multirow{2}{*}{ TÉCNICA } & \multicolumn{2}{|c|}{ GÊNERO } & \multicolumn{2}{c|}{ FAIXA ETÁRIA } & \multirow{2}{*}{ TOTAL } \\
\cline { 2 - 6 } & Feminino & Masculino & Adolescente & Adulto & Idoso & \\
\hline Questionário & 48 & 48 & 3 & 93 & - & 96 \\
Entrevista & 12 & 13 & - & 15 & 10 & 25 \\
Total & 60 & 61 & 3 & 108 & 10 & \\
\hline Total de participantes & \multicolumn{7}{|l}{} \\
\hline
\end{tabular}


Os dados obtidos no questionário foram analisados por meio de testes estatísticos não paramétricos no programa estatístico SPSS/PC (Statistical Package for Social Sciences). Os seguintes testes descritivos e inferenciais foram realizados:

(a) frequências, que revelam a distribuição de dados de acordo com as categorias consideradas;

(b) teste de correlação Spearman, que indica a força e a direção em que duas variáveis ordinais se relacionam; e

(c) teste Kendall $W$, que fornece um índice de divergência na concordância (ranking) através dos valores de Mean Rank (ROWNTREE, 1981).

Os dados das entrevistas foram analisados por meio da análise de conteúdo, utilizando a categorização, a descrição e a interpretação (BARDIN, 1977).

\section{Descrição do obj eto de estudo}

Como objeto de estudo, foi selecionado o Parque Zoológico da Fundação Zoobotânica do Rio Grande do Sul (FZB/RS), conhecido como Zoo Sapucaia, localizado em Sapucaia do Sul, Rio Grande do Sul, Brasil, a 30 quilômetros da capital do Estado, Porto Alegre (Figura 4). O Parque Zoológico é formado por uma área total de 780 hectares, sendo 620 pertencentes à Reserva Florestal Padre Balduíno Rambo e 160 hectares pelo zoológico propriamente dito, com uma área de visitação de 50 hectares. O Parque localiza-se longe do centro urbano de Sapucaia do Sul, e possui acesso pela BR-118, uma estrada movimentada e sem ciclovia, o que dificulta o seu acesso por meios não motorizados. É possível chegar ao Zoológico por transporte público, ainda que o trem não passe no Zoológico. O visitante pode utilizar o trem para ir até a Estação Sapucaia, pegar a "Lotação 7, zoológico", descer e atravessar a estrada pela passarela.

No levantamento físico do Parque Zoológico foi produzido o mapa geral do espaço (Figura 5) e evidenciadas as características físicas e espaciais do Parque Zoológico de acordo com as sete categorias de elementos físicos de design.

Quanto às instalações de apoio aos visitantes (1), o ambiente físico, aberto ao público, conta com bilheteria, estacionamento, um restaurante (Figura 6a), quiosques de informações e de comercialização de alimentos, sanitários, centro de educação ambiental, áreas de descanso e piquenique. Apresenta variados tipos de recintos (2), inclusive alguns de grades de ferro, ainda da década de 1960. As barreiras mais comuns são os de malha metálica (Figura 6b), mas fossos secos e com água também podem ser encontrados (Figura 6c). Elementos de enriquecimento ambiental também estão presentes em todos os recintos.

Em relação à vegetação e aos recursos naturais (3), o espaço é caracterizado pela presença de muita vegetação nativa, trilhas e locais totalmente preservados. A vegetação ornamental se faz presente em grande parte das áreas (Figura 6d). Há um grande lago em destaque (Figura 6e), além dos lagos dentro dos recintos de animais. Mobiliários (4) como bancos e lixeiras são comuns e bem distribuídos. Há grande variedade de design desses elementos, o que demonstra que foram implantados no ambiente em diferentes tempos. Como recurso recreativo (5) há uma praça infantil e um trenzinho para fotos (Figura 6f).

\section{Figura 4 - Localização do Parque Zoológico da FZB/RS, em vermelho}

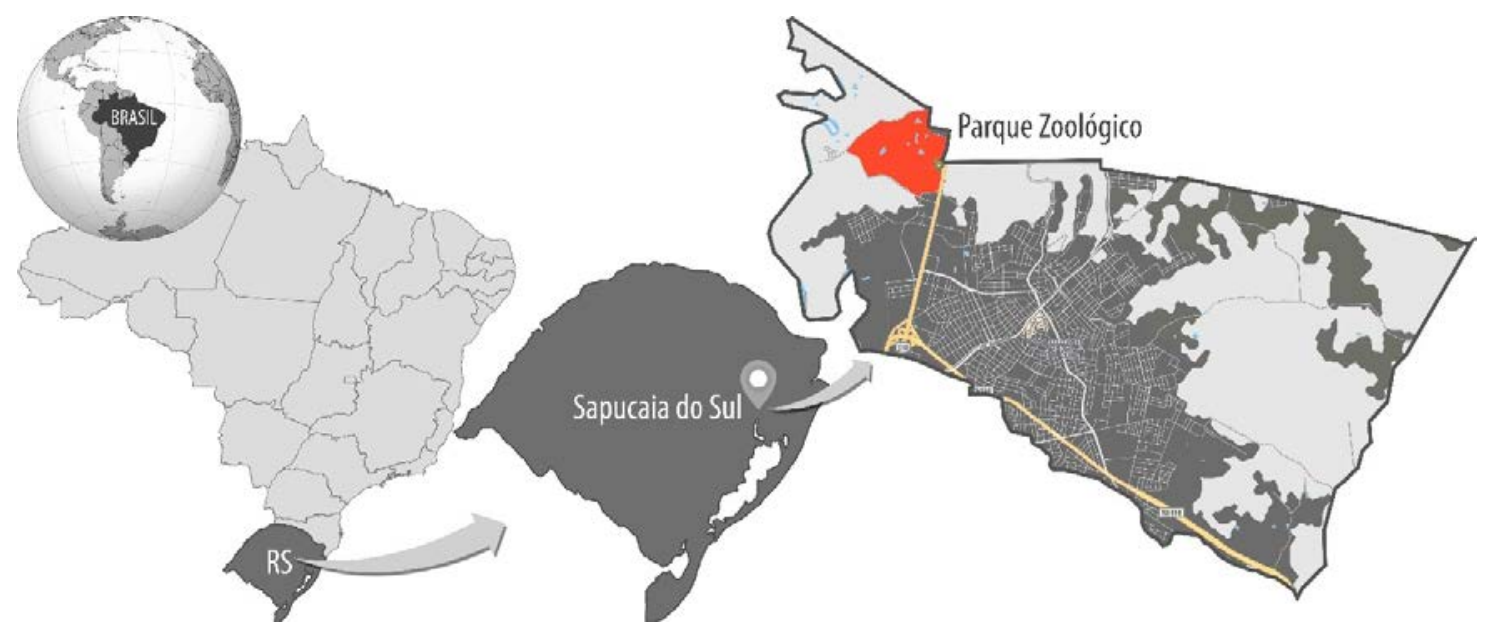

Fonte: adaptado do Google Earth (2017). 


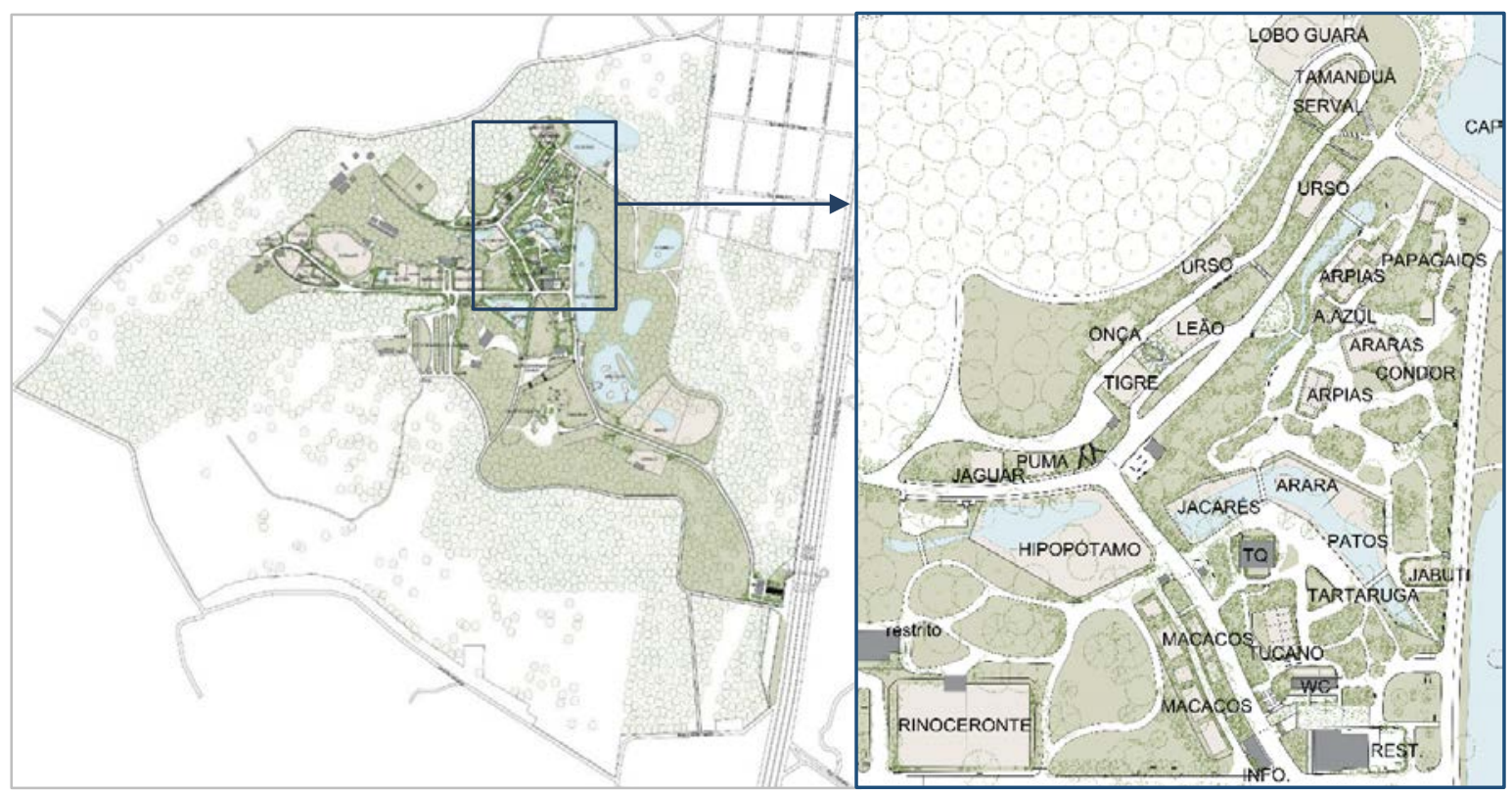

Quanto aos elementos de circulação (6), encontram-se variados tipos de caminhos, com diferentes tipos de pavimentação, mas a maior parte é de terra batida (Figura 6g). Faltam demarcações limites na área dos recintos e sinalização, pois alguns caminhos levam o visitante para as trilhas ou a saída. Muitos caminhos não possuem acessibilidade. Pontes, escadarias e trapiches (Figura 6h) são elementos presentes. Dispositivos de orientação espacial (7), como sinalização direcional e mapas “você está aqui” (Figura 6i) são encontrados em vários pontos do jardim zoológico. Sinalizações educativas estão presentes em todos os recintos.

\section{Resultados e discussões}

A amostra desse estudo compreendeu 121 respondentes, visitantes do Parque Zoológico da FZB/RS, sendo 29,2\% visitantes de primeira vez e $70,8 \%$ reincidentes (Figura 7a). Como caracterização da amostra, destaca-se que 2,5\% dos participantes são adolescentes, 89,3\% são adultos e 8,3\% são idosos (Figura 7b). Em relação ao gênero, 50,4\% dos respondentes são do gênero masculino e 49,6\% do feminino (Figura 7c). Quanto ao meio de transporte utilizado para ir ao Zoológico, 91,7\% dos respondentes afirmaram ter ido de carro e 8,3\% afirmaram ter ido de ônibus de excursão (Figura 7c). Nenhum participante da pesquisa afirmou ter ido a pé, de bicicleta, ou de ônibus/trem para a visitação.

Considerando os resultados obtidos por meio do questionário, afirma-se que os visitantes do jardim zoológico em estudo estão muito satisfeitos ou satisfeitos $(84,4 \%)$ com os espaços abertos do Parque Zoológico. Os dados sobre reincidência confirmam indiretamente essa informação, visto que as pessoas tendem a não retornar a lugares que consideram insatisfatórios ou desqualificados. A seguir são definidos quais aspectos dos espaços abertos do jardim zoológico em estudo, que estão relacionados à satisfação dos visitantes.

\section{Avaliação da agradabilidade, organização e interesse}

Verificou-se que as categorias agradabilidade, organização e interesse são influentes na satisfação dos visitantes com os espaços abertos do jardim zoológico em estudo. Os dados apontam que 86,4\% dos respondentes consideram o Parque Zoológico muito agradável ou agradável e 68,8\% o consideram muito organizado ou organizado. Referente ao interesse, verificou-se que 93,8\% dos respondentes consideram o espaço aberto do Parque Zoológico muito interessante ou interessante. Foram encontradas correlações estatisticamente significativas entre as percepções dos visitantes quanto ao nível de satisfação do espaço com a aparência estética (agradabilidade) (Spearman, coef $=0,615$, sig $=0,000$ ), com sua organização (Spearman, coef $=0,484$, sig $=0,000$ ) e com o interesse (Spearman, coef $=0,338$, sig=0,000). Percebeu-se que quanto maior a agradabilidade, organização e interesse percebido do espaço, maior será a satisfação geral com o ambiente. 


\section{Avaliação das instalações de apoio aos visitantes}

Em relação às instalações de apoio aos visitantes, foram encontradas correlações estatisticamente significativas médias entre o nível de satisfação geral com a visita e a satisfação com as áreas de exposição (Spearman, coef $=0,494$, sig $=0,000$ ), com as áreas de estacionamentos (Spearman, coef $=0,455$, sig=0,000), com as áreas de piquenique/descanso (Spearman, coef $=0,384$, sig=0,000), com a área da pracinha (Spearman, coef $=0,406$, sig=0,000), e correlação fraca com a área de alimentação (Spearman, coef $=0,214$, sig=0,036). Percebeu-se que quanto maior a satisfação com todas as áreas, e não apenas as áreas de exposição, maior será a satisfação geral com o espaço.

Figura 6 - Conhecendo o Parque Zoológico

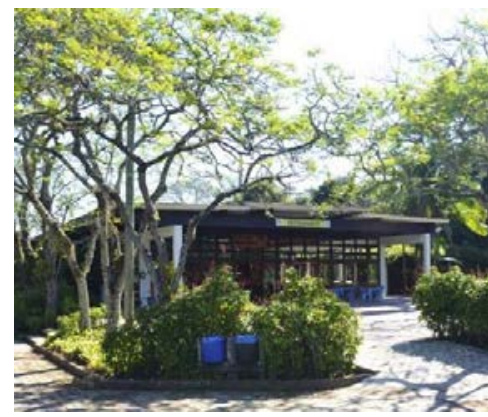

(a) Restaurante

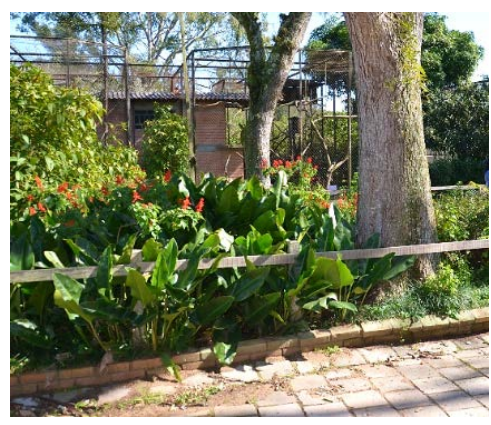

(d) Vegetação ornamental

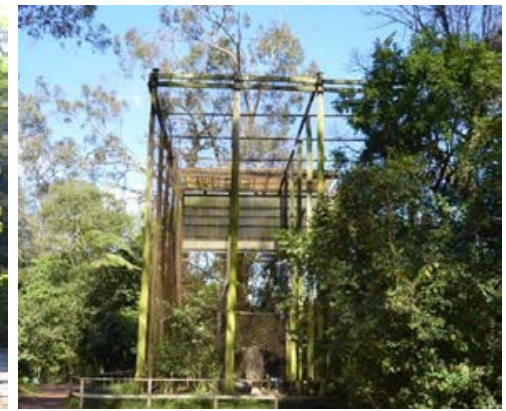

(b) Recintos de malha metálica

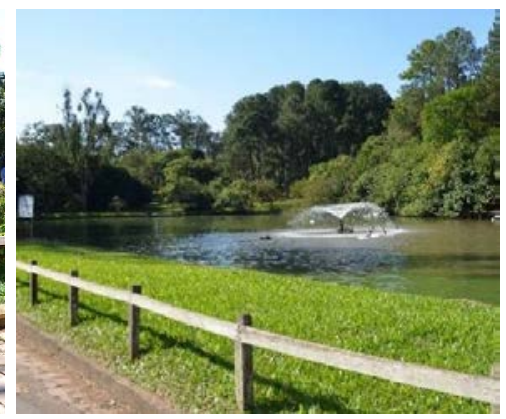

(e) Lago

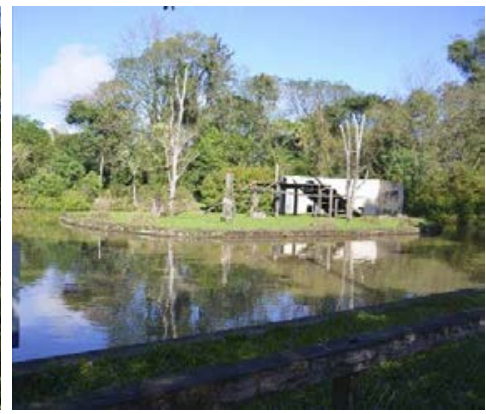

(c) Recinto com lago

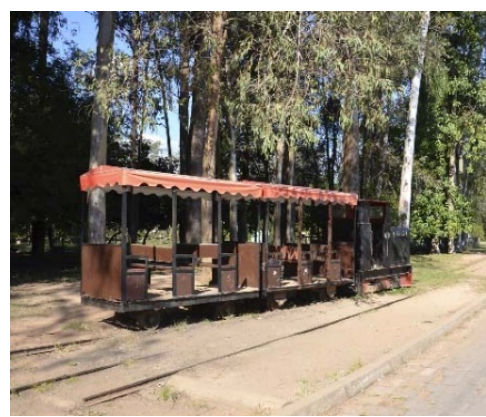

(f) Trenzinho

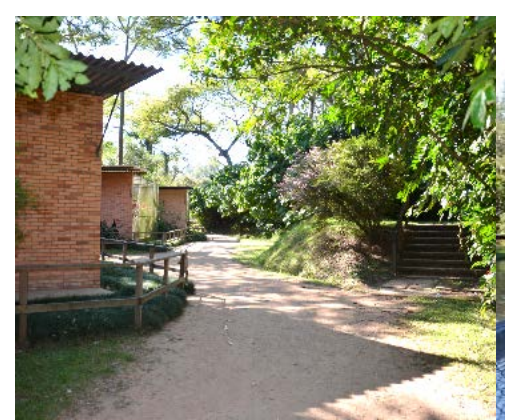

(g) Caminhos de terra batida

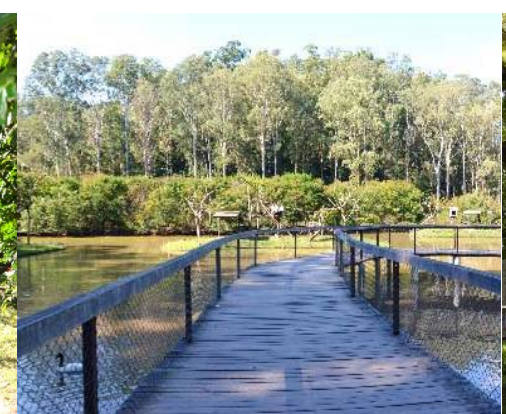

(h) Trapiche do lago

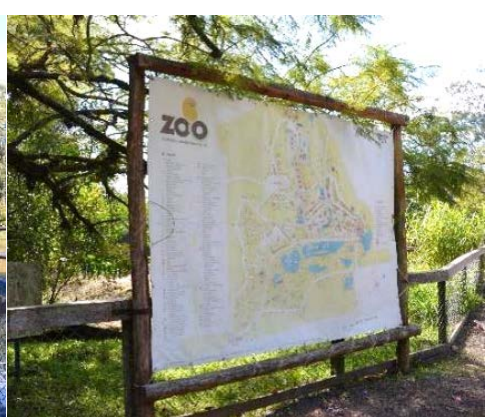

(i) Mapa "Você-está-aqui”" 
Figura 7 - Caracterização da amostra

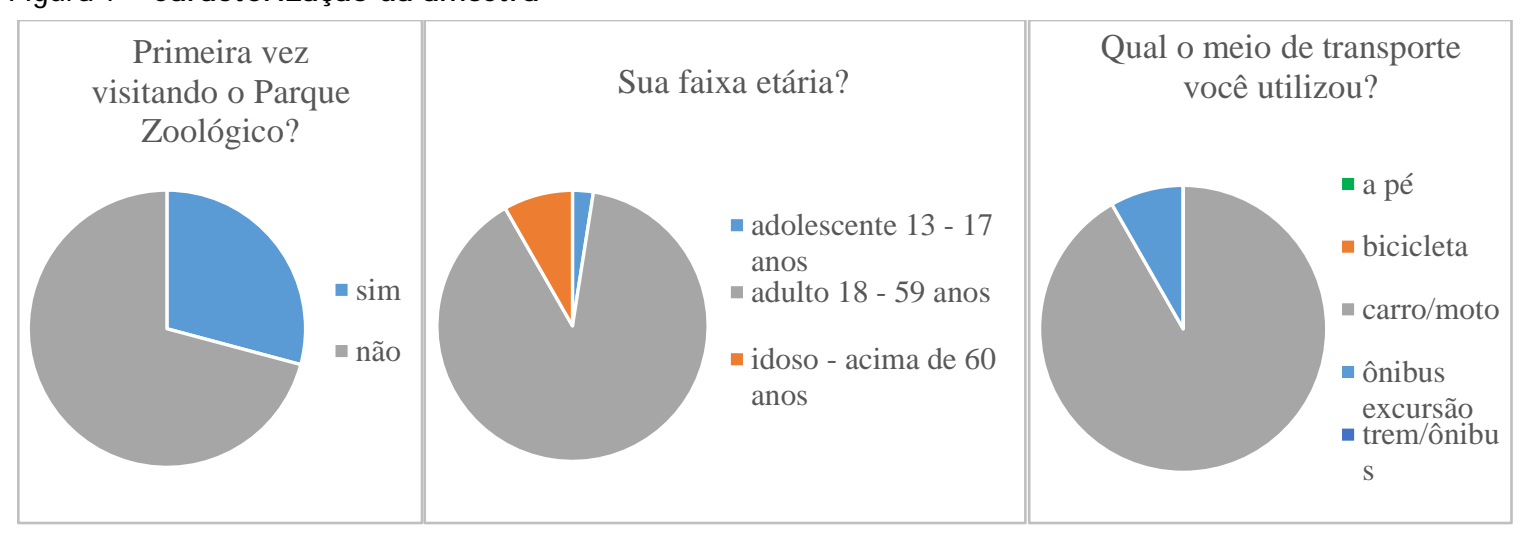

(a) Tipo de visitante

(b) Faixa etária

(c) Gênero

Com a realização do teste Kendall $W$ entre as instalações de apoio secundárias (excluindo as áreas de exposição), foi evidenciado o ranking de peso avaliativo entre as áreas. As áreas de estacionamento foram avaliadas como muito satisfatórias ou satisfatórias por $75 \%$ dos respondentes, e adquiriram o maior peso avaliativo (M. Rank =3,31), ficando na primeira colocação. As áreas de piquenique/descanso foram avaliadas como muito satisfatórias ou satisfatórias por 70,8\% dos respondentes, e ficaram na segunda colocação (M. Rank=3,22) seguidas pela área da pracinha, avaliada como muito satisfatória ou satisfatória somente por pouco mais da metade dos respondentes. A área de alimentação foi conceituada mais negativamente que as demais em termos de satisfação, sendo avaliada neutra ou insatisfatoriamente por $56,2 \%$ dos respondentes, e adquiriu o menor peso avaliativo no ranking ( $M$. Rank=2,45) (Tabela 2). Nas entrevistas foi constatado que a insatisfação com a área de alimentação não está relacionada às suas questões físicas e configuracionais, mas $\operatorname{sim} \operatorname{com}$ a inadequação dos produtos vendidos e seus valores. Acredita-se que a área de alimentação, que proporciona uma vista privilegiada do lago e abundância de vegetação ornamental, seria mais positivamente avaliada caso não houvesse a interferência de outros fatores.

\section{Avaliação de importância de determinadas características de design}

Os resultados obtidos demonstram que todas as características de design citadas foram avaliadas como muito importante e importante, entre $63,6 \%$ e $89,6 \%$. No entanto, os dados evidenciaram rankings (Mean Rank) diferentes entre elas (Tabela 3).
De acordo com os dados obtidos, destacam-se como mais importantes para a satisfação dos visitantes as características relacionadas à naturalidade do espaço. Sendo os três primeiros colocados no ranking, respectivamente, a "presença de vegetação" (M. Rank=6,88), a "visualização dos animais" (M. Rank=6,03) e a "presença de lagos e riachos” ( $M$. Rank 5,92). A visualização dos animais, que poderia se esperar que ocupasse a primeira colocação devido ao valor previamente atribuído aos animais, por se tratar de um jardim zoológico, ocupa a segunda colocação no ranking de importância. Constata-se que estar perto dos animais e ter uma boa visualização deles é importante para os visitantes, mas não tanto quanto à vegetação do lugar. A "diversidade de ambientes" ficou na quarta colocação (M. Rank 5,80) seguida pelos "lugares para explorar a natureza", em quinto (M. Rank=5,36). Quanto às características com menor peso avaliativo, tem-se as relacionadas aos caminhos e sinalização do Parque Zoológico. Verifica-se que mapas e placas de indicação de caminhos ( $\left.6^{\mathrm{a}}\right)$ (M. Rank=5,27), caminhos divertidos $\left(7^{\mathrm{a}}\right) \quad(M . \quad$ Rank $=5,10)$ acessibilidade $\left(9^{\mathrm{a}}\right) \quad(M$. Rank $=4,98)$ e largura e tipo de pavimentação $\left(10^{\text {a }}\right.$ colocada no ranking) (M. Rank=4,48) são menos importantes na satisfação dos visitantes com o espaço aberto do Parque Zoológico.

Em uma avaliação mais específica, verificou-se o nível de agradabilidade da vegetação e das fontes de água do Parque Zoológico. Como resultado, obteve-se que essas características são avaliadas pelos visitantes como muito agradáveis ou agradáveis (vegetação: 93,7\% e fontes de água: 82,3\%). A avaliação um pouco menos favorável das fontes de água pode estar relacionada ao fato de alguns lagos do Parque Zoológico possuírem animais vivendo neles, não sendo usados apenas como uma barreira física entre pessoas e animais ou como elemento isolado. Verificou-se também que 
há uma correlação estatisticamente significativa média entre as percepções dos visitantes quanto à agradabilidade da vegetação (Spearman, coef $=0,473$, sig=0,000) e das fontes de água (Spearman, coef $=0,412, \quad \operatorname{sig}=0,000$ ) com a satisfação geral do espaço. Percebeu-se que quanto maior a agradabilidade (aparência) da vegetação e das fontes de água, maior será a satisfação geral com o espaço aberto do Parque Zoológico. A naturalidade do espaço também é destacada nas entrevistas como o aspecto que os visitantes mais gostaram no Parque Zoológico: Eu gostei porque parece uma fazenda, é mais natural e [..] não é tão artificial, é uma coisa bem natural” (Entrevistado adulto $n^{\circ} 1$ ); "Gostei de ver que tem bastante natureza. Tem bastante... uma boa área que parece ser de vegetação nativa. E, achei legal. Achei que tem bastante verde" (Entrevistado adulto $n^{\circ} 4$ ); "Ah, [...] é que tem essa, esse ambiente aberto, [...] tem bastante árvore que tu te sente confortável. A vegetação é bem importante, porque se não, não tem como tu visitar todo o espaço em baixo de sol também, né" (Entrevistado adulto $n^{\circ}$ 9).

\section{Avaliação dos mobiliários: bancos e lixeiras}

$\mathrm{Na}$ avaliação da disponibilidade de bancos e lixeiras, as respostas dos visitantes foram contraditórias. Em relação a bancos, grande parte dos visitantes considerou a sua quantidade suficiente e outra grande parte os considera insuficientes (respectivamente 54,5\% e 38\% dos respondentes). Há um total de 79 bancos no Parque Zoológico e a maior parte deles estão colocados individualmente e não em conjuntos, o que pode se tornar negativo para grupos com mais de 3 pessoas. Percebe-se durante uma visita ao Parque Zoológico que grandes grupos tentam usar outros meios para se acomodarem no espaço. Estes levam suas próprias cadeiras e sentam à beira da área do lago, ou os indivíduos mais novos, ou em casais, sentamse no colo um dos outros, ou sentam-se em toalhas levadas por eles mesmos nas áreas de piquenique para descansar. Não foi encontrada relação estatisticamente significativa entre a avaliação da disponibilidade de bancos com a satisfação geral.

Em relação às lixeiras, há um total de 56 lixeiras no Parque Zoológico, e sua disponibilidade foi avaliada de maneira mais positiva que os bancos. A maior parte dos participantes $(61,1 \%)$ considera sua quantidade muito suficiente ou suficiente, mas existe também uma grande quantidade de indicações negativas (32,2\%). Foi encontrada uma relação estatisticamente significativa entre a disponibilidade de lixeiras com a satisfação geral (Spearman, coef $=0,335$, sig=0,001). Quanto maior for a satisfação com a disponibilidade apenas de lixeiras, maior será o grau de satisfação geral com a visita.

Em relação à aparência dos bancos e das lixeiras disponíveis no Parque Zoológico, somente metade dos respondentes os considera muito agradáveis ou agradáveis (49\% e 50\% respectivamente). Existe ainda uma considerável parte dos respondentes que os considera nem agradáveis, nem desagradáveis (29,2\% para ambos), ou desagradáveis/muito desagradáveis (respectivamente 21,9\% e 20,8\%). Esse fato pode ter ocorrido por não haver uma padronização desses elementos no Parque Zoológico e, dependendo da área, podem ser encontradas tipologias diferentes tanto em questões de design quanto de manutenção. Percebe-se que alguns visitantes são mais propícios a lembrar da aparência negativa desses elementos, enquanto outros focam apenas na parte positiva ou não se importam com a aparência deles. Verificou-se que há correlações estatisticamente significativas, porém fracas, entre as percepções dos visitantes quanto à agradabilidade do mobiliário e à satisfação geral do espaço (Bancos: Spearman, coef $=0,339$, sig $=0,001$; Lixeiras: Spearman, coef $=0,225$, sig=0,012). Assim, quanto maior a agradabilidade do mobiliário, maior será o nível de satisfação geral do espaço.

Tabela 2 - Avaliação das instalações de apoio secundárias do Parque Zoológico da FZB/RS

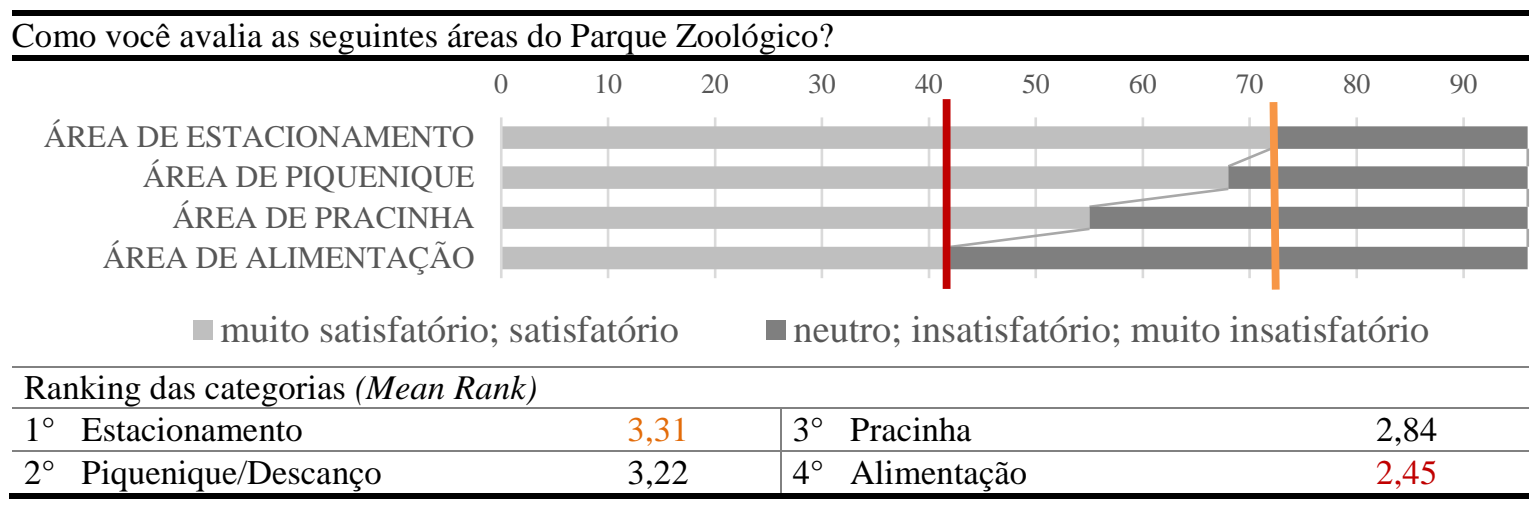


Tabela 3 - Avaliação da importância de diversas características de design dos espaços abertos do Parque Zoológico da FZB/RS

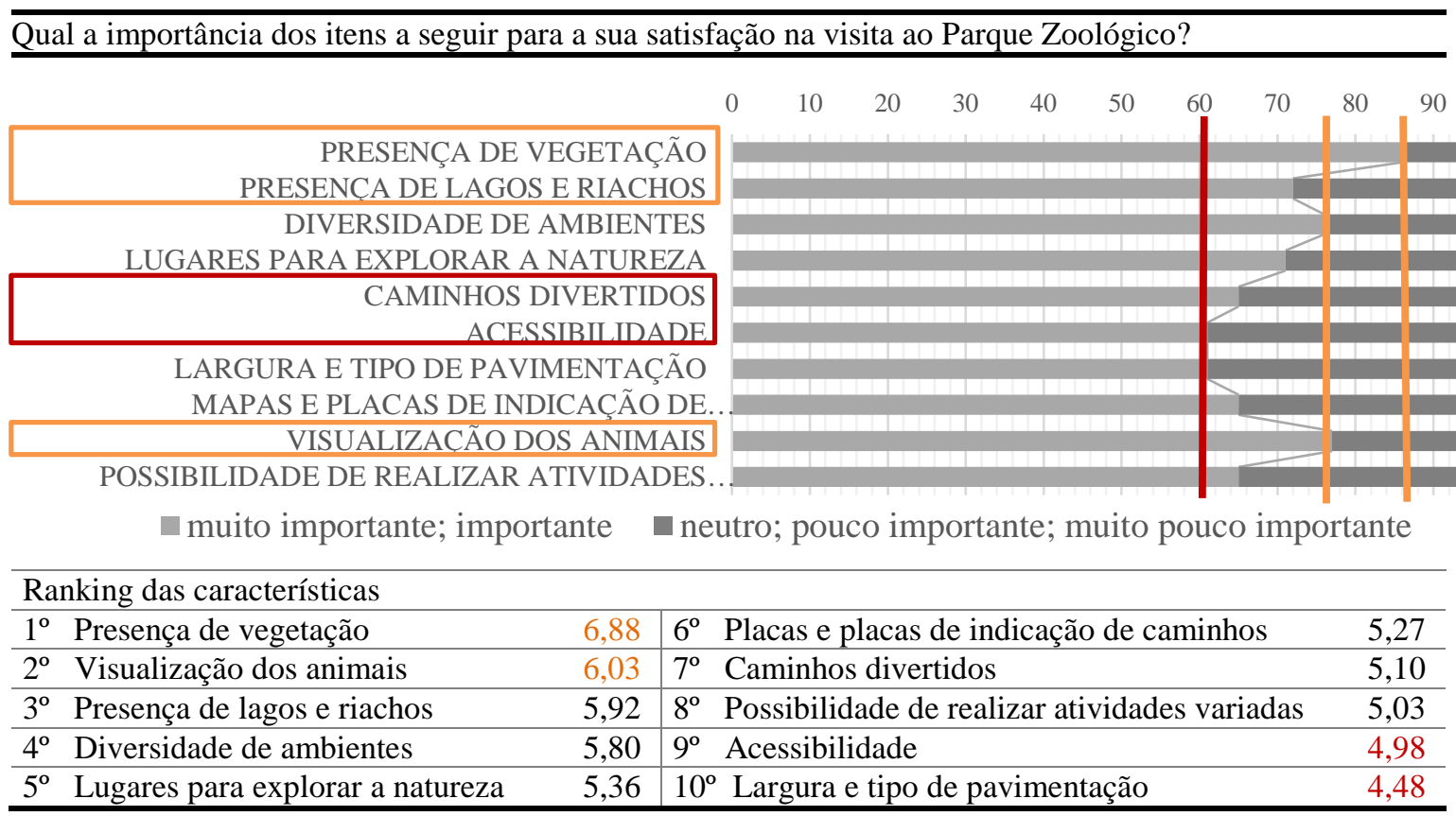

\section{Insatisfação dos visitantes e seus desejos para o espaço}

Embora a avaliação do Parque Zoológico tenha sido majoritariamente positiva, $15,7 \%$ dos participantes do estudo não ficaram satisfeitos com a visita. Quanto aos aspectos de que os visitantes menos gostaram, destacam-se os recintos dos animais, e incluem-se nesse aspecto as características físicas dos recintos e os animais propriamente ditos. Quanto aos aspectos físicos, a principal reclamação é a relacionada ao tamanho dos recintos e à distância a ser percorrida entre eles. Quanto aos animais propriamente ditos, a principal reclamação é a sua quantidade ou ausência. Muitos dos visitantes esperavam encontrar animais específicos na visita, mas não os encontraram. Percebe-se, a partir das respostas dadas à pergunta sobre os aspectos de que não gostaram, que se o visitante chega ao local e não encontra o animal que ele esperava que ali estivesse, sua percepção do espaço torna-se inexistente, e considera que naquela determinada área não havia nada. Ou seja, o visitante fica frustrado por não encontrar o animal que está procurando e assim não percebe mais nada em sua volta e vai embora insatisfeito. É importante destacar que o que motivou a visita de $61,5 \%$ dos respondentes foi a vontade de ver e se divertir com os animais. Além da reclamação quanto aos animais, foi apontada nas entrevistas a necessidade de maior limpeza e recolhimento de lixo, pois ainda que encontrassem lixeiras durante o passeio, muitas delas estavam cheias.
Também foram citados aspectos dos quais os visitantes sentiram falta durante a visitação, destacando-se a questão da sinalização espacial do Parque Zoológico, ou seja, os visitantes apontaram a necessidade de colocação de mais placas direcionais e informativas. Ademais, houve respostas que refletiam a necessidade de uma loja de lembrancinhas, um pedalinho, carros elétricos, mais quiosques de alimentação com comida saudável e não apenas sorvetes e frituras, bancos, banheiros, bebedouros, áreas de lazer, mais locais de churrasqueira, indicação de local para primeiros socorros, caixas eletrônicos, acessibilidade e possibilidade de visitas guiadas. Essas respostas requerem um estudo mais detalhado no futuro.

\section{Considerações finais}

Este estudo buscou identificar, a partir da percepção dos seus visitantes, quais aspectos dos espaços abertos de jardins zoológicos estão mais fortemente ligados à percepção de qualidade ambiental e como eles contribuem para seu reconhecimento como um lugar qualificado.

Verificou-se haver correlação entre a satisfação dos visitantes com os níveis de agradabilidade, organização e interesse proporcionados pelo espaço. Assim, conclui-se que quanto mais agradável, organizado e interessante for o espaço aberto maior será a satisfação do visitante.

Verificou-se também que quanto maior for a satisfação com todas as áreas de visitação, sendo 
elas áreas de exposição, estacionamento, alimentação, piquenique/descanso e pracinhas, maior será o grau de satisfação geral com a visita, e que não apenas as áreas de exposição de animais interferem na satisfação dos visitantes. Essa informação está de acordo com as afirmações de Sausman (1982) e Ebenhöh (1992) de que para tornar a visita ao jardim zoológico aprazível, é necessário que o espaço tenha diversas instalações de apoio disponíveis ao público. Além disso, encontram-se também com as afirmações de Ebenhöh (1992) de que os zoológicos são lugares onde a caminhada é geralmente necessária e, sendo assim, áreas de descanso para os visitantes são muito importantes. Destaca-se que o peso de importância dado ao estacionamento pode estar relacionado à dificuldade de acesso ao Parque Zoológico por meios não motorizados. Acredita-se que se as possibilidades de acesso fossem diferentes, os visitantes não teriam dado tal importância à área do estacionamento.

Em relação à análise do grau de importância das características de design citadas na satisfação com o espaço, verificou-se que existem diferenças na avaliação dos visitantes. A característica destacada como a mais importante para a satisfação com o espaço aberto é a presença de vegetação, seguida pela visualização dos animais e pela presença de lagos e riachos (relacionadas com a naturalidade). Verificou-se que o nível de satisfação com o espaço depende do grau de agradabilidade da vegetação e das fontes de água, e assim quanto mais agradáveis a vegetação e as fontes de água forem consideradas, maior será a satisfação geral. Fatores como as sombras de árvores e a presença de lagos são aspectos de grande apreciação pelos visitantes e que interferem na sua satisfação. Essas informações estão de acordo com as afirmações de Ebenhöh (1992), de que em jardins zoológicos a água e a vegetação, além dos animais, estão entre os aspectos mais importantes para os visitantes, e que a presença de vegetação e de água influenciam na boa aparência do espaço, e assim influenciam na satisfação.

No outro extremo, entre as características apontadas como menos importantes para a satisfação são a acessibilidade e a largura e o tipo de pavimentação de caminhos. Essa informação vai ao encontro das afirmações de Graetz (1995), de que como os jardins zoológicos são locais naturalistas, já é esperado que não haja o desenho universal em todos os locais. Desse modo, os indivíduos que necessitam desse desenho já sabem que ele não está disponível no espaço, e assim não fazem a visita.

Em relação aos mobiliários, verificou-se que a inadequação da quantidade de bancos não influencia na satisfação geral dos visitantes. Houve divergências na avaliação, e isso provavelmente pelo fato, como aponta Ebenhöh (1992), da variedade do número de indivíduos e da heterogeneidade dos grupos de visitantes dos jardins zoológicos, pois muitas vezes apenas alguma parte do grupo quer descansar, enquanto os membros mais enérgicos querem desfrutar das atividades. A influência apenas das lixeiras para a satisfação dos visitantes faz um contraponto às afirmações de Francis (2003), de que bancos e lixeiras (ambos) influenciam na satisfação das pessoas com o espaço. Quanto à aparência deles, verificou-se que o nível de satisfação geral dos espaços abertos de jardins zoológicos é influenciado pela agradabilidade do seu mobiliário, e, assim, quanto maior for a satisfação com a aparência dos bancos e lixeiras maior será o nível de satisfação geral. Essa informação está de acordo com as afirmações de Kaplan e Kaplan (1983), de que, entre outros elementos, a aparência dos bancos e lixeiras influenciam na agradabilidade do ambiente.

Desse modo, revelam-se os aspectos físicoespaciais que mais influenciaram na satisfação dos visitantes para o estudo de caso. Verificou-se que existe influência dos aspectos físicos pesquisados, na satisfação dos visitantes com o espaço aberto, e que, apesar dos animais possuírem grande influência na qualidade da visitação e na satisfação com a visita, os elementos físico-espaciais desses ambientes também influenciam fortemente na qualidade espacial e na satisfação das pessoas. Através das análises e dos levantamentos realizados neste estudo, buscou-se contribuir para a formulação do que seria um jardim zoológico qualificado. Espera-se que os resultados obtidos nesse estudo da área de pesquisa das Relações Ambiente-Comportamento contribuam para a qualificação dos ambientes de jardins zoológicos.

O presente trabalho foi realizado com apoio da Coordenação de Aperfeiçoamento de Pessoal de Nível Superior - Brasil (Capes) - Código de Financiamento 001.

\section{Referências}

ASSOCIAÇÃO BRASILEIRA DE NORMAS TÉCNICAS. NBR ISO 9000: sistemas de gestão da qualidade: fundamentos e vocabulário. Rio de Janeiro, 2015.

BARATAY, E.; HARDOUIN-FUGIER, E. Zoo: a history of zoological gardens in the west. London: London: Reaktion Books, 2002.

BARDIN, L. Análise de Conteúdo. Lisboa: Edições 70, 1977. 
BITGOOD, S. An Overview of the Methodology of Visitor Studies. Visitor behavior, Jacksonville, v. 3, n. 3, 1988.

CASTello, L. A Percepção do Lugar. Porto Alegre: Ed. da UFRGS, 2007.

COE, J. (ed.). Environmentalism in Landscape Architecture. Washington, D.C.: Dumbarton Oaks Research Library and Collection, 2000. v. 22.

COE, J. Zoo Environments for People, Plants and Animals. In: WORKSHOP FOR INDIAN ZOO DIRECTORS, CENTRAL ZOO AUTHORITY OF INDIA: DESIGNING ENCLOSURES AND LANDSCAPE PLANNING FOR INDIAN ZOOS, India, 2011. Proceedings... India, 2011.

COE, J. Design and Architecture: third Generation conservation, post-immersion and beyond. In: FUTURE OF ZOOS SYMPOSIUM, New York, 2012. Proceedings... New York, 2012.

DEL RIO, V. Introdução ao Desenho Urbano no Processo de Planejamento. São Paulo: Pini, 1990.

EBENHÖH, M. Evaluating Zoo Design: the importance of visitor studies. Vienna, 1992. $132 \mathrm{f}$. Dissertation (Master of Landscape Architecture) University of Agricultural Sciences, Vienna, 1992.

FRANCIS, M. Urban Open Spaces: designing for user needs. Washington: Island Press, 2003.

GAGNE, R. The Conditions of Learning and Theory of Instruction. $4^{\text {th }}$ ed. New York: CBS College Publishing, 1985.

GRAETZ, M. The Role of Architectural Design in Promoting the Social Objectives of Zoos: a study of zoo exhibit design with reference to selected exhibits in Singapore zoological gardens. Singapore, 1995. 163 f. Dissertation (Master of Architecture) - National University of Singapore, Singapore, 1995.

GOLLEDGE, R.; STIMSOM, R. J. Spatial

Behavior: a geographic perspective. Nova York: Guilford Press, 1997.

HAAS, K. E. Espaços Abertos: indicadores da apropriação interna e a adaptação dos usuários do entorno. Porto Alegre, 2000. Dissertação (Mestrado em Planejamento Urbano e Regional) Faculdade de Arquitetura e Urbanismo, Universidade Federal do Rio Grande do Sul, Porto Alegre, 2000.
HANCOCKS, D. Different Nature: the paradoxical world of zoos and their uncertain future. Berkeley: University of California Press, 2003.

KAPLAN, R.; KAPLAN, S. Cognition and Environment: functioning in an uncertain world. Ann Arbor: Ulrich's Bookstore, 1983.

LANG, J. Creating Architectural Theory. New York: Van Nostrand Reinhold, 1987.

NASAR, J. L. Environmental Aesthetics: theory, research and applications. Cambridge: University Press, 1992.

ORNSTEIN, S. W.; ROMÉRO, M. (col.).

Avaliação Pós-Ocupação do Ambiente Construído. São Paulo: Studio Nobel; Ed. USP, 1992.

REIS, A. T.; LAY, M. C. D. Avaliação da Qualidade de Projetos: uma abordagem perceptiva e cognitiva. Ambiente Construído, Porto Alegre, v. 6, n. 3, p. 21-34, jul./set. 2006.

RHEINGANTZ, P. A. et al. Observando a Qualidade do Lugar: procedimentos para a avaliação pós-ocupação. Rio de Janeiro: PROARQ - Universidade Federal do Rio de Janeiro, 2009.

ROBINETTE, C. et al. Zoos and Public Health: a partnership on the One Health frontier. Journal One Health, v.3, p. 1-4, 2017.

ROWNTREE, D. Statistics Without Tears. Londres: Penguin, 1981.

SAUSMAN, K. Zoological Park and Aquarium Fundamentals. Wheeling: American Association of Zoological Parks and Aquariums, 1982.

STAMPS, A. Psychology and the Aesthetics of the Built Environment. New York: Kluwer Academic Publishers, 2000.

WEBER, R. On the Aesthetics of Architecture, a Psychological Approach to the Structure and the Order of Perceived Architectural Space. London: Avebury, 1995.

WILLIAMS, L. R. et al. The Accuracy of Behavioral Data Collected by Visitors in a Zoo Environment: Can Visitors Collect Meaningful Data? International Journal of Zoology, 13 p., 2012. 


\section{Samantha Balleste}

Curso Técnico de Edificações | Instituto Federal Sul-Rio-Grandense | Praça Vinte de Setembro, Centro, Campus Pelotas | Pelotas - RS Brasil | CEP 96015-360 | Tel.: (53) 2123-1000 | E-mail: samantha_balleste@hotmail.com

\section{Natalia Naoumova}

Faculdade de Arquitetura e Urbanismo | Universidade Federal de Pelotas | Rua Benjamin Constant, 1359, Centro | Pelotas - RS - Brasil | CEP 96010-020| Tel.: (53) 3284-5500 | E-mail: naoumova@gmail.com

\section{Revista Ambiente Construído}

Associação Nacional de Tecnologia do Ambiente Construído

Av. Osvaldo Aranha, 99 - 3o andar, Centro

Porto Alegre - RS - Brasil

CEP 90035-190

Telefone: +55 (51) 3308-4084

Fax: +55 (51) 3308-4054

www. seer. ufrgs. br/ ambienteconstruido

E-mail: ambienteconstruido@ufrgs.br

(c) (i)

This is an open-access article distributed under the terms of the Creative Commons Attribution License. 